\title{
Suboccipital segment of the vertebral artery: A cadaveric study
}

\author{
S. Muralimohan, Anil Pande, M. C. Vasudevan, Ravi Ramamurthi \\ Department of Neurosurgery, Post Graduate Institute of Neurological Surgery, ALNC, VHS Hospital, Taramani, Chennai - 600 113, India
}

\section{Address for correspondence:}

Dr. S. Muralimohan,

No. 51, $3^{\text {rd }}$ Cross,

Brindavan Layout, Vijinapuram,

Bangalore - 560 016, India.

E-mail: drmurali78@gmail.com

\begin{abstract}
Objective: To study the course, relationships, branches and possible anomalies of the vertebral artery in the suboccipital region in adult Indian cadavers. Materials and Methods: Twenty-one suboccipital segment vertebral artery specimens from embalmed, Indian adult cadavers were dissected and studied. Dissection was performed using microsurgical instruments and was carried out from the skin up to the vertebral artery in layers. The course, relationships and the branches of the vertebral artery were studied and measurements were taken using Vernier calipers. The readings obtained were corroborated with the measurements derived from the digital images using a computer. Observations: All the vertebral arteries had a tortuous course and were covered with rich venous plexuses. None of the specimens had an anomalous course. The artery was divided into a vertical segment ( $\mathrm{Vv}$ ) between $\mathrm{C} 2$ and $\mathrm{Cl}$ vertebra and a horizontal segment $(\mathrm{Vh})$ from the $\mathrm{Cl}$ transverse foramina to its dural entry. The mean diameter of the artery was $4.8 \mathrm{~mm}$. The shortest distance of $\mathrm{Vv}$ segment from the dural tube was $16.1 \mathrm{~mm}$, and the distance from the $\mathrm{C} 2$ ganglion was $7.2 \mathrm{~mm}$. The average length of the $\mathrm{Vv}$ segment was $15 \mathrm{~mm}$ and the average length of the $\mathrm{Vh}$ segment was $35.6 \mathrm{~mm}$. The average of the shortest distance between the vertebral artery and the midline was $13.4 \mathrm{~mm}$. Conclusion: The vertebral artery has a tortuous course and is prone to accidental iatrogenic injury, which can result in devastating neurological sequelae depending on contralateral vertebral artery flow. A thorough anatomical knowledge of this segment is essential for the surgeon who intends to operate in this area.
\end{abstract}

Key words: Cadaveric study, suboccipital cavernous sinus, vertebral artery dissection was carried out from the skin up to the VA, in layers. A midline incision was made from the EOP up to the $\mathrm{C7}$ spinous process and further dissection carried out. The muscular layers were dissected, defined and reflected laterally exposing the suboccipital region. The spinous process of the axis and the posterior arch of the atlas were then visualized. The transverse process of $\mathrm{C} 1$ was identified along with the attachment of the superior and inferior oblique muscles. There is an area filled with loose areolar tissue caudal to the lower border of the inferior oblique muscle, between $\mathrm{C} 1$ and $\mathrm{C} 2$. Using blunt dissection in this area, the ventral ramus of C2 nerve root was identified and traced anteriorly, which coursed around the vertebral artery [Figure 1]. Rich venous plexus covered this segment of the vertebral artery. The suboccipital muscles were then removed and the entire posterior arch of the $\mathrm{C} 1$ was dissected subperiosteally up to the transverse processes on either 


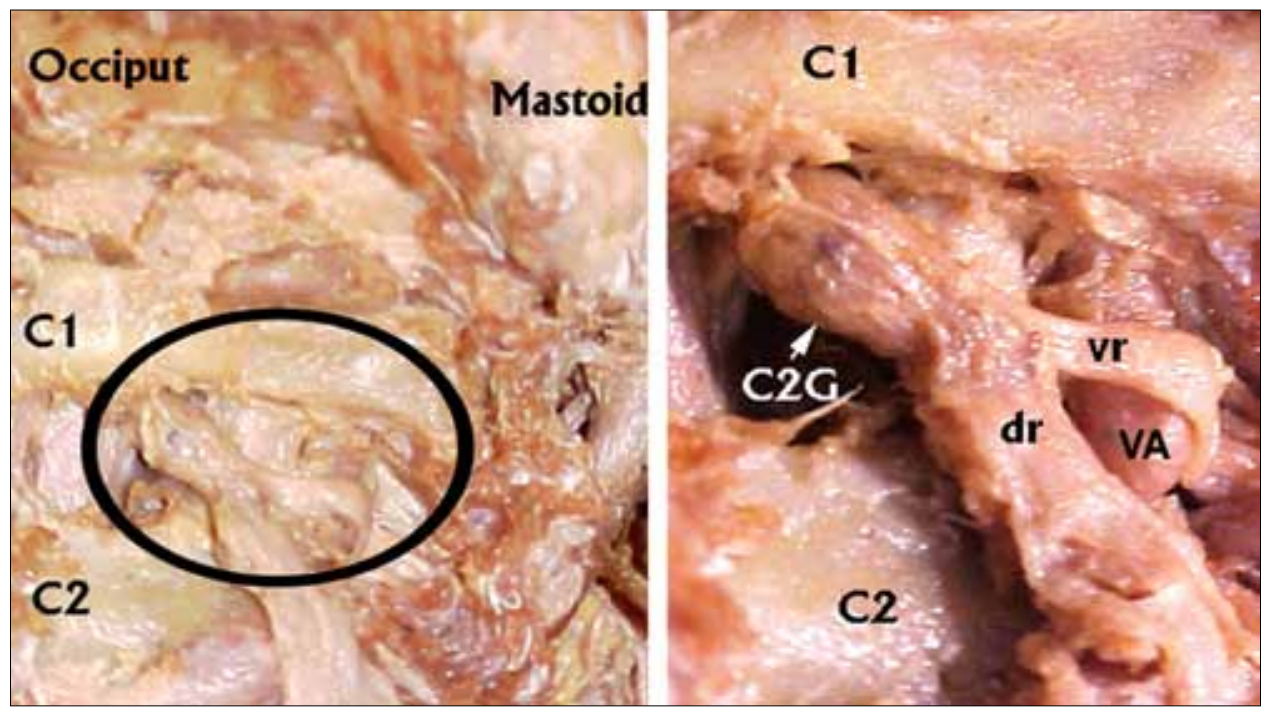

Figure 1: Loose areolar tissue fills the space b/n C1 posterior arch and C2 lamina, on dissection of which the C2 spinal nerve and ganglion, its division into dorsal and ventral rami can be appreciated (marked area). The ventral rami when traced anteriorly leads to the vertebral artery

side. The VA was then dissected and followed upto its dural entry point [Figure 2]. The bony landmarks were defined and digital photographs were taken. The course, relationships and the branches of the VA were studied and measurements were taken using Vernier calipers with accuracy of $0.1 \mathrm{~mm}$. The readings obtained were then corroborated with the measurements derived from the digital images on a computer. The measured parameters [Table 1] were analyzed statistically and compared with previous studies.

\section{Results}

In all specimens, the VA had a tortuous course and was covered with rich venous plexuses [Figure 3]. A well-defined periosteal sheath encased the VA at the transverse foramina. None of the specimens had an anomalous course. For convenience of description and measurements, the artery was divided into two segments: Vv and Vh segment [Figure 4]. Vv segment runs between $\mathrm{C} 2$ and $\mathrm{C} 1$ and has a 'vertical course', while the segment of the artery exiting from $\mathrm{C} 1$ transverse foramina up to its dural entry with a 'horizontal course' was labeled as Vh segment.

\section{Vv segment}

The VA exits from the transverse foramen of the axis and ascends up in a tortuous course in close relation to the atlanto-axial joint [Figure 5]. It initially takes a lateral bend, designated as Loop 1 and then straightens up (Loop 2) to enter the transverse foramen of atlas. It is densely covered by venous plexuses and is in close relation with the anterior ramus of the $\mathrm{C} 2$ nerve root, which runs around the artery from posterior to anterior. The mean length of this segment was $15.0 \mathrm{~mm}$ (SD 1.53), with a range of $12.6 \mathrm{~mm}$ to $17.4 \mathrm{~mm}$ and a median

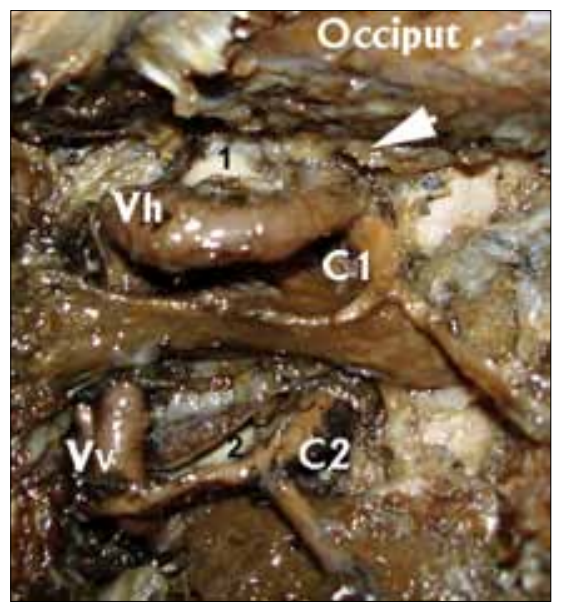

Figure 2: Course of the suboccipital segment of the vertebral artery (Vv-vertical and Vh - horizontal segment). Arrow head indicates the point of dural entry of the artery. C1 and C2 spinal nerves, occipito-atlantal joint (1) and atlanto-axial joint (2) can be appreciated

Table 1: Comparison of present study with available literature (measurement in $\mathrm{mm}$ )

\begin{tabular}{|c|c|c|c|c|}
\hline & $\begin{array}{c}\text { EL barry } \\
\text { et al. } \\
\text { (1995) }\end{array}$ & $\begin{array}{c}\text { Goel } \\
\text { et al. } \\
(2004) \\
\end{array}$ & $\begin{array}{l}\text { Lang } \\
\text { et al. } \\
\text { (1991) } \\
\end{array}$ & $\begin{array}{l}\text { Present } \\
\text { study }\end{array}$ \\
\hline $\begin{array}{l}\text { Length of Vv segment } \\
\text { (b/n C1 and C2) }\end{array}$ & - & 15.7 & 38.9 & 15.04 \\
\hline $\begin{array}{l}\text { Length of Vh segment } \\
\text { (From C1 to dural entry } \\
\text { point) }\end{array}$ & - & 35.7 & 44.3 & 35.57 \\
\hline $\begin{array}{l}\text { Distance of } \mathrm{V} v \text { from } \mathrm{C} 2 \\
\text { ganglion }\end{array}$ & - & 7.5 & - & 7.23 \\
\hline $\begin{array}{l}\text { Distance of } \mathrm{Vv} \text { from } \\
\text { lateral end of dural tube }\end{array}$ & 16.8 & 15.3 & 17.02 & 16.13 \\
\hline $\begin{array}{l}\text { Distance of Vh from } \\
\text { midline }\end{array}$ & - & - & - & 13.24 \\
\hline $\begin{array}{l}\text { Distance of Vh from } \\
\text { mastoid tip }\end{array}$ & 21 & - & - & 20.5 \\
\hline $\begin{array}{l}\text { Distance } \mathrm{b} / \mathrm{n} \text { mastoid tip } \\
\text { and } \mathrm{C} 1 \text { transverse process }\end{array}$ & 19.6 & - & - & 19.6 \\
\hline Diameter of VA & 4 & - & 4.2 & 4.8 \\
\hline
\end{tabular}



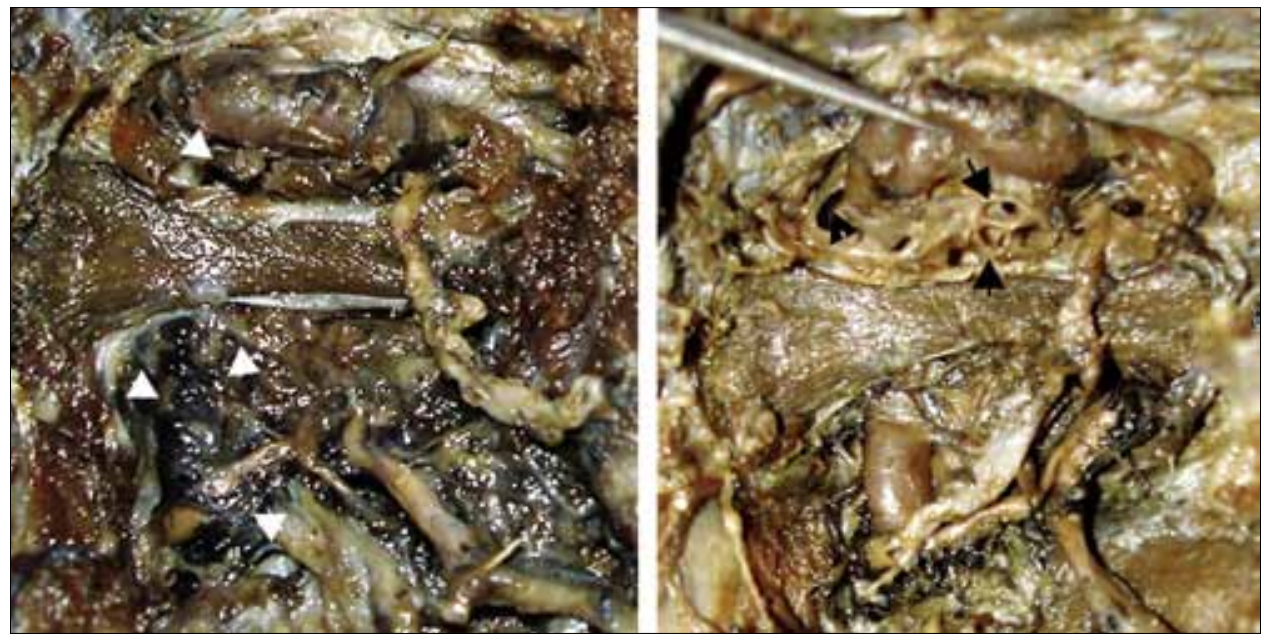

Figure 3: Venous plexus (arrow heads) around the $\mathrm{Vv}$ and $\mathrm{Vh}$ segment
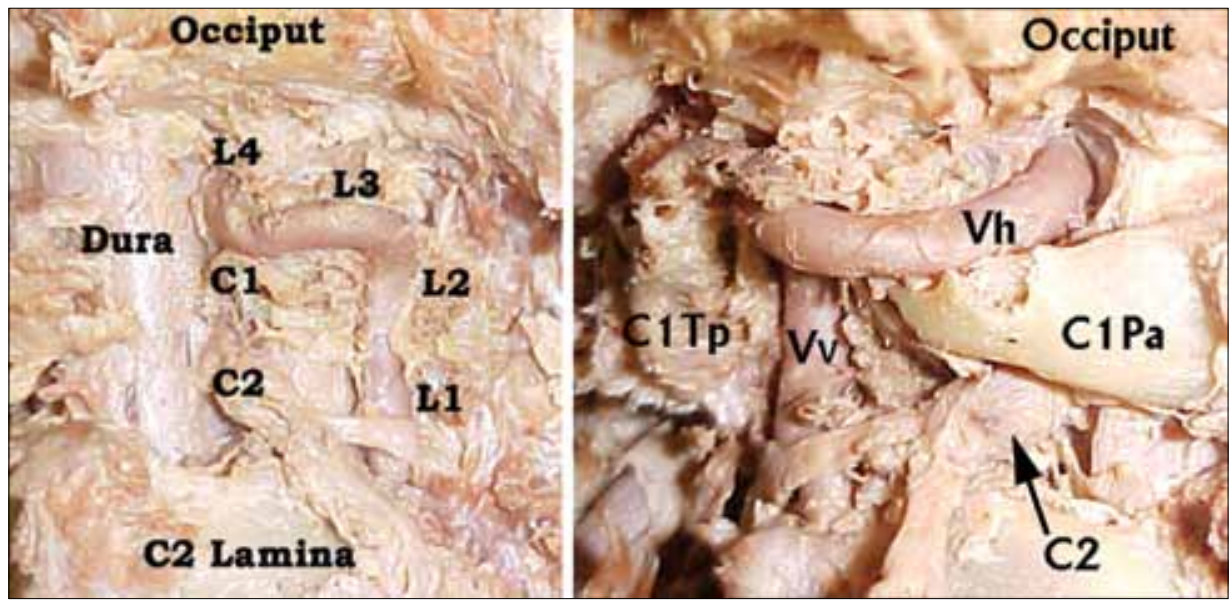

Figure 4: Course of the suboccipital segment of the vertebral artery (V3). The C1 posterior arch has been removed, exposing the dural tube and C2 ganglion. The division into vertical (Vv) and horizontal (Vh) segments, four loops of V3 (L1-4), C1 transverse process (C1Tp), C1 posterior arch (C1Pa) and C2 Lamina can be appreciated

value of $15.2 \mathrm{~mm}$. The artery was at a mean distance of $7.2 \mathrm{~mm}$ (SD 0.75) from the C2 cervical ganglion, with a range of $5.9 \mathrm{~mm}$ to $8.4 \mathrm{~mm}$ and a median value of $7.4 \mathrm{~mm}$. The artery was at a mean distance of $16.1 \mathrm{~mm}$ (SD 0.98) from the lateral border of the dural tube, with a range of $14.7 \mathrm{~mm}$ to $17.3 \mathrm{~mm}$ and a median value of $16.2 \mathrm{~mm}$. The artery had a mean circumference of $15.0 \mathrm{~mm}$ (SD 2.63) with a range of $9.2 \mathrm{~mm}$ to $20.2 \mathrm{~mm}$ and a median value of $16.2 \mathrm{~mm}$. The calculated mean diameter was $4.8 \mathrm{~mm}$. This segment gave a prominent radiculomuscular branch, which divided into radicular and a muscular branch [Figure 6]. A well-defined tough periosteal sheath surrounded the VA and its venous plexus in the transversary canal in all the specimens. This sheath protected the artery from damage during removal of the posterior wall of the transversary canal using a drill [Figure 7].

\section{Vh segment}

After its exit from the $\mathrm{C} 1$ transverse foramen, the artery follows a horizontal course, immediately changing its direction posteriorly and medially. The artery then arches around the lateral mass of $\mathrm{C} 1$ to enter the VA groove on the $\mathrm{C} 1$ posterior arch (Loop 3). As the artery enters the VA groove, it changes its direction and curves anteriorly and medially to reach the dural entry point (Loop 4). There is a tough fibro-periosteal sheath that bridges the edges of the VA groove, converting it into a tunnel. In one cadaver this bridging fibrous tissue was completely ossified on the right side forming a bony tunnel [Figure 8] and was partially ossified on the left side. The $\mathrm{C} 1$ nerve root courses posterior and inferior to the atlantal part of the artery. The branches arising from this segment were inconsistent; there were muscular and dural branches, but the posterior inferior cerebellar artery did not arise extradurally in any of the specimens. A rich venous plexus cushions this segment of the artery. The mean length of this segment was $35.6 \mathrm{~mm}$ (SD 2.44), with a range of $31.5 \mathrm{~mm}$ to $40 \mathrm{~mm}$ and a median value of $35.6 \mathrm{~mm}$. The artery was at a mean distance of $20.5 \mathrm{~mm}$ (SD 3.0) from the mastoid tip, with a range of $16 \mathrm{~mm}$ to $27.4 \mathrm{~mm}$ and a median value of $19.6 \mathrm{~mm}$. The artery 


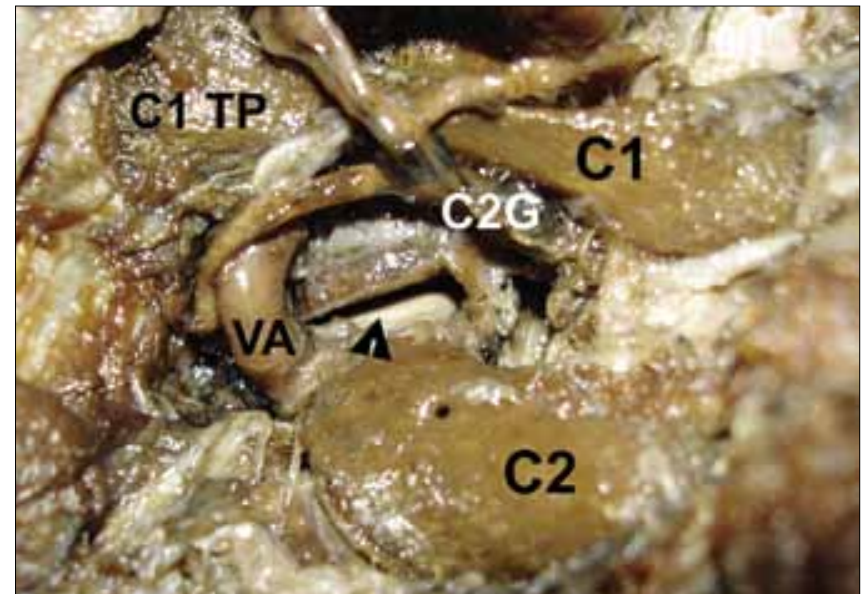

Figure 5: Vv segment is closely related to C1- C2 joint. The C2 nerve along with its ganglion (C2G) has been retracted and the joint capsule dissected to expose the joint cavity (block arrow). The $\mathrm{C} 1$ posterior arch, C1 transverse process (C1TP) and C2 lamina can be appreciated

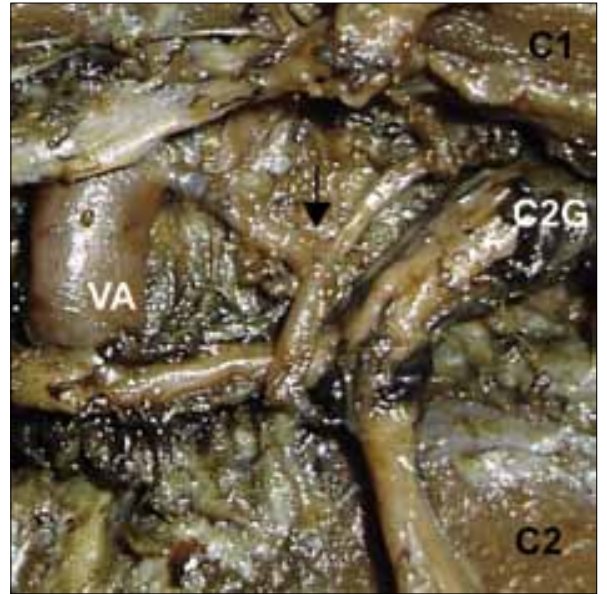

Figure 6: Radiculomuscular branch (arrow) arising from Vv segment of VA. Its division into the radicular and muscular branches can be appreciated. The $\mathrm{C} 2$ ganglion (C2G) along with its ventral and dorsal rami is also seen
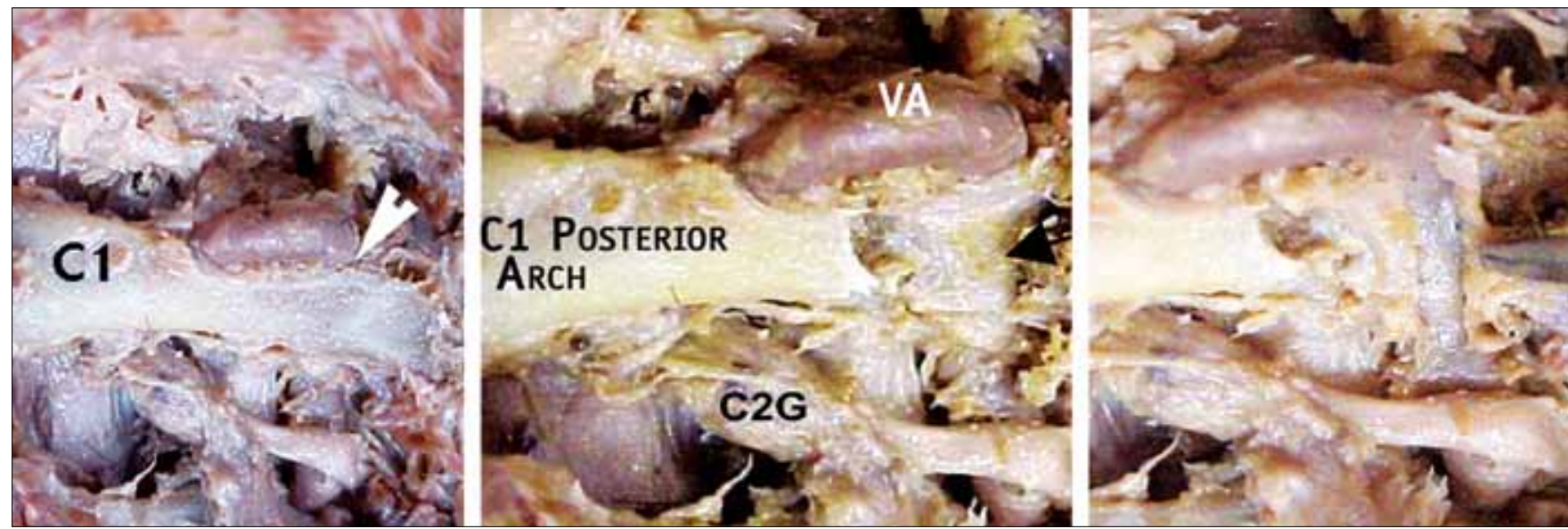

Figure 7: The posterior wall of the transverse foramina of atlas has been removed exposing the periosteal sleeve (block arrow) encasing the vertebral artery
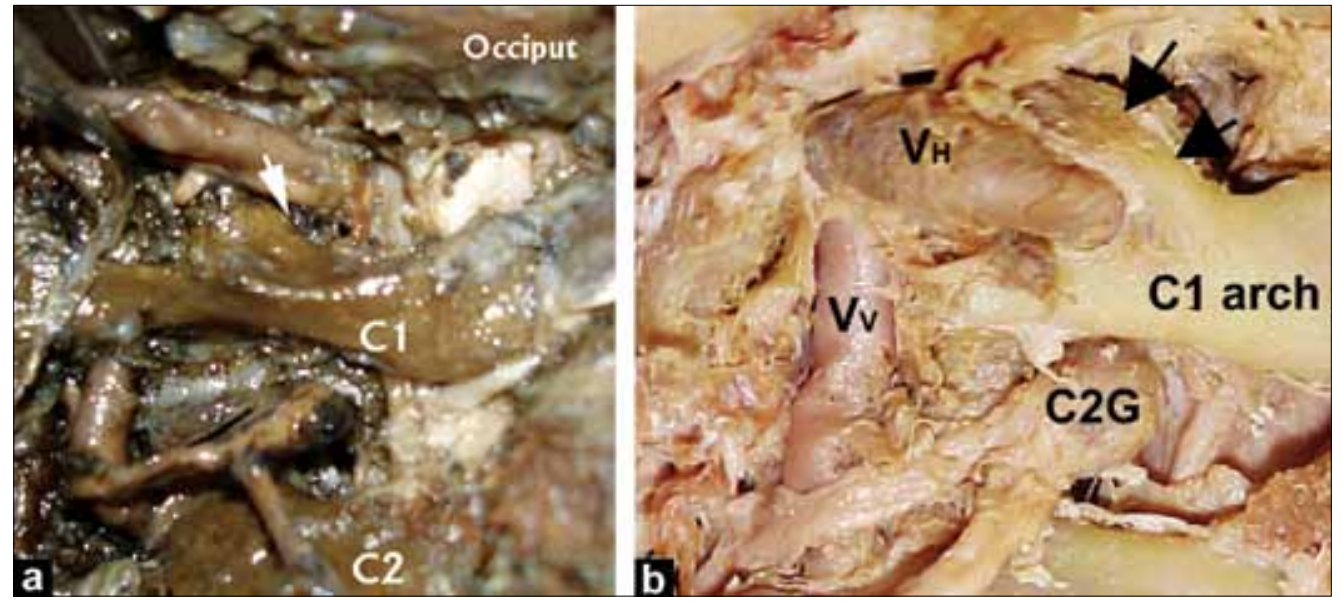

Figure 8: (a) Vh portion of the VA usually rests in a groove over the superior surface of the posterior arch of atlas (white arrow); (b) Anomalous ossification of the fibrous canal (black arrow) over the VA groove on the atlas. The Vh is seen traversing this ossified tunnel. The posterior wall of the transverse foramina of atlas has been removed. The $\mathrm{C} 1, \mathrm{C} 2$ lamina, $\mathrm{C} 2$ ganglion (C2G) and the dura can be appreciated

was at a mean distance of $13.4 \mathrm{~mm}$ (SD 2.0) from its dural entry point to the midline, with a range of 9.5 to $18.2 \mathrm{~mm}$ and a median value of $13.0 \mathrm{~mm}$. The mean length of the artery that curves posterior to the lateral mass of the atlas, from its exit at the transverse foramen at $\mathrm{C} 1$ up to the VA tunnel on the posterior atlantal arch was $16.1 \mathrm{~mm}$ (SD 1.23) with a range of 13.8 to $18.5 \mathrm{~mm}$ and a median value of $16.1 \mathrm{~mm}$. 


\section{Discussion}

Suboccipital segment of the VA has a tortuous course with multiple loops unlike its other segments, possibly to accommodate the wide movements occurring at craniovertebral junction. ${ }^{[1,2]}$ However, this makes the artery prone to iatrogenic injury during surgical procedures like lateral mass fixation, posterior-circulation revascularization and various approaches to $\mathrm{CV}$ junction, such as midline posterior, far lateral, retromastoid-suboccipital and transcondylar approaches. ${ }^{[3-10]}$ Sekhar et al. reported their experience with the lateral transcondylar approach in 22 patients, out of which there was VA injury in four patients. Aggressive retraction and accidental injury were the reasons for VA injury. The arterial anatomy had been distorted either by the tumor or due to prior treatment in three cases. In one case the injury occurred at the $\mathrm{C} 2$ foramen during attempted transposition of the vessel. ${ }^{[2]}$ The typical course of the VA carries the vessel in proximity to the ideal screw trajectory during C1-C2 transarticular screw fixation. ${ }^{[7]}$ Wright and Lauryssen in their retrospective survey of the American Association of Neurological Surgeons/Congress of Neurological Surgeons section of disorders of the spine and peripheral nerves, on VA injury in C1-2 transarticular screw fixation, reported 31 cases of known VA injury and 23 cases of suspected VA injury during the surgical procedure. Additionally, the incidence of VA anomalies in the atlantoaxial region is $2.3 \%$, therefore, a thorough understanding of the three-dimensional anatomy of this arterial segment is imperative for the surgeon in order to avoid accidental injury to the artery. Intraoperative injury to the VA can lead to catastrophic bleeding and compromise of cerebral blood flow, causing unpredictable neurological deficits depending on contralateral VA flow. ${ }^{[8]}$

The VA originates from the supero-posterior aspect of the subclavian artery. It ascends and enters the transverse foramen of the $\mathrm{C} 6$ vertebra. This segment is designated as V1. It then ascends through the transverse foramina of C6 up to $\mathrm{C} 2$ in a linear fashion, this segment is designated as V2. After its exit from C2 transverse foramen, the artery adopts a serpentine and tortuous course in relation to the CVJ and becomes intracranial by piercing the dura and arachnoid at the level of the atlanto-occipital joint. This segment has been conventionally termed as V3 or the suboccipital segment. Once intracranial, the arteries on either side curve around the medulla and courses anteriorly to join each other to form the basilar trunk at the lower end of the pons. This segment is termed as V4..$^{[2,11]}$ The VA is frequently asymmetric. Sometimes, the minor VA is too small to be detected by angiography and may end in the posterior inferior cerebellar artery. If this minor VA ends in the basilar trunk it is termed as 'hypoplastic' and if not connected to the basilar artery it is termed as 'atretic'. Sometimes the artery may be completely absent, in which case it is frequently replaced by a persistent congenital anastomosis, the proatlantal artery.

El-Bary et al., in their study on 14 cadaveric specimens, observed that the VA was at an average distance of $21 \mathrm{~mm}$ from the mastoid tip, and the distance of the mastoid tip from the tip of the $\mathrm{C} 1$ transverse process was $19.6 \mathrm{~mm}$. The average diameter of the artery was $4 \mathrm{~mm}$ on the left side and $3.9 \mathrm{~mm}$ on the right side, and the shortest distance of the VA from the midline was $16.8 \mathrm{~mm} \cdot{ }^{[12]}$ Goel et al. in their cadaveric study on 20 specimens found the average length of the $\mathrm{Vv}$ segment to be $15.7 \mathrm{~mm}$, the distance of the Vv segment from the $\mathrm{C} 2$ ganglia and the dural tube was $7.5 \mathrm{~mm}$ and $15.3 \mathrm{~mm}$, respectively. The average length of the Vh segment was $35.7 \mathrm{~mm} \cdot{ }^{[2]}$ Lang et al..$^{[1]}$ observed the paramedian distance of the VA from its dural entry point to be $11.8 \mathrm{~mm}$ and Ebraheim et al.$^{[13]}$ observed the distance of the VA from the midline on the posterior aspect of the $\mathrm{C} 1$ arch to be $12 \mathrm{~mm}$. We found the average paramedian distance from the dural entry point to be $13 \mathrm{~mm}$, though the range was from $9.5 \mathrm{~mm}$ to $18.2 \mathrm{~mm}$.

Rhoton noted that the VA was partially covered by the posterior atlanto-occipital membrane and the bony groove was transformed into a bony canal that completely surrounds a short segment of the artery. Of the 50 arteries he examined, $24(48 \%)$ were in a shallow groove, $12(24 \%)$ were partially, but incompletely, surrounded by bone, and $14(28 \%)$ coursed through a bony ring that completely surrounded the artery. ${ }^{[14]}$ Senoglu et al. in their study on 166 dry $\mathrm{C} 1$ specimens noted that eight had complete bilateral and 10 had unilateral osseous bridges, forming a canal on the superior surface of the posterior arch of C1. ${ }^{[15]}$ In our study, we found the bridging fibrous tissue to be completely ossified on the right side forming a bony tunnel and incompletely on the left side in one cadaver. Though anatomical variations may potentially increase the rate of intraoperative complications, this osseous bridge is more likely to reduce the risk of injury as it constitutes an additional barrier protecting the artery.

There is a well-defined periosteal sheath which surrounds the vertebral artery and its venous plexus in the transversary canal. This was found to be a tough and well-defined layer in our study. Transposition of the VA requires removal of the posterior wall of the transversary canal. Bruneau et al. advocated the use of kerrison punch for bone removal. The same may be performed using a drill with diamond burr as the artery is well protected by this periosteal sheath within the canal; however, caution has to be exercised to prevent accidental slippage and injury to the adjacent segment of the vessel. ${ }^{[16]}$

The venous compartment in the suboccipital region has been termed as suboccipital cavernous sinus, as its structure is strikingly similar to the cavernous sinus. It is bordered 
proximally by the lateral ring, distally by the distal (dural) ring, inferiorly by the posterior arch of the atlas, ventrally by the dura and the capsule of the atlanto-occipital condylar joint and dorsally by the posterior atlanto-occipital membrane. It is surrounded by a fibrous membrane and contains the Vh, the muscular artery of the V3h, the posterior meningeal artery, the periarterial autonomic neural plexus and the $\mathrm{C} 1$ nerve. It communicates with the contralateral sinus via the internal vertebral venous plexus, the occipital sinus via the marginal sinus, the jugular bulb and vein via the anterior, lateral and posterior condylar veins. ${ }^{[17]}$ Brisk venous bleed encountered during surgery in this region must caution the proximity to the VA.

\section{Conclusion}

- VA in the suboccipital region has a tortuous course and is prone to accidental iatrogenic injury. It is surrounded by rich venous plexus; hence brisk venous bleed encountered during surgery in this region must caution the proximity to the VA.

- The average paramedian distance of VA at C1 arch was found to be $13 \mathrm{~mm}$, with the shortest distance being $9.5 \mathrm{~mm}$. Hence the safe limit for C1 laminectomy without encountering the vertebral arteries is $9.5 \mathrm{~mm}$ from the midline on either side.

- Drilling of the transverse foramina required for mobilization of the artery may be performed using a diamond burr as the vertebral artery is covered and protected by a tough periosteal sleeve within the transversary canal. However, caution needs to be exercised as accidental slippage might injure the adjacent segment of the vessel.

\section{References}

1. Lang J, Kessler B. About the suboccipital part of the vertebral artery and the neighboring bone-joint and nerve relationships. Skull Base Surg
1991;1:64-72.

2. Cacciola F, Phalke U, Goel A. Vertebral artery in relationship to C1-C2 vertebrae: An anatomical study. Neurol India 2004;52:178-84.

3. Al-Mefty O, Borba LA, Aoki N, Angtuaco E, Pait TG. The transcondylar approach to extradural nonneoplastic lesions of the craniovertebral junction. J Neurosurg 1996;84:1-6.

4. Babu RP, Sekhar LN, Wright DC. Extreme lateral transcondylar approach: Technical improvements and lessons learned. J Neurosurg 1994;81:49-59.

5. Banerji D, Behari S, Jain VK, Pandey T, Chhabra DK. Extreme lateral transcondylar approach to the skull base. Neurol India 1999;47:22-30.

6. George B, Dematons C, Cophignon J. Lateral approach to the anterior portion of the foramen magnum. Application to surgical removal of 14 benign tumors: Technical note. Surg Neurol 1988;29:484-90.

7. Hakuba A, Tsujimoto T. Transcondylar approach for foramen magnum meningiomas. In: Sekhar LN, Janecka IP, editors. Surgery of cranial base tumours. New York: Raven Press; 1993. p. 671-8.

8. Heros RC. Lateral suboceipital approach for vertebral and vertebrobasilar artery lesions. J Neurosurg 1986;64:559-62.

9. Sen CN, Sekhar LN. An extreme lateral approach to intradural lesions of the cervical spine and foramen magnum. Neurosurgery 1990;27:197-204.

10. Wright NM, Lauryssen C. Vertebral artery injury in C1-2 transarticular screw fixation: Results of a survey of the AANS/CNS section on disorders of the spine and peripheral nerves. American Association of Neurological Surgeons/Congress of Neurological Surgeons. J Neurosurg 1998;88:634-40.

11. Gabella G Cardiovascular system. In: Peter L Williams, editor: Grays Anatomy, the anatomical basis of medicine and surgery. $38^{\text {th }}$ ed. London: Churchill Livingstone; 1999. p. 1530-1.

12. Abd el-Bary TH, Dujovny M, Ausman JI. Microsurgical anatomy of the atlantal part of the vertebral artery. Surg Neurol 1995;44:392-400.

13. Ebraheim NA, Xu R, Ahmad M: The quantitative anatomy of the vertebral artery groove of the atlas and its relation to the posterior atlantoaxial approach. Spine 1998;23:320-3.

14. De Oliveira E, Rhoton AL Jr, Peace D. Microsurgical anatomy in the region of the foramen magnum. Surg Neurol 1985;24:293-352.

15. Senoglu M, Gumusalan Y, Yuksel KZ, Uzel M, Celik M, Ozbag D: The effect of posterior bridging of $\mathrm{C}-1$ on craniovertebral junction surgery. J Neurosurg Spine 2006;5:50-52.

16. Bruneau M, Cornelius JF, George B. Anterolateral approach to the V3 segment of the vertebral artery. Neurosurgery 2006;58:29-35.

17. Arnautovic KI, al-Mefty O, Pait TG, Krisht AF, Husain MM. The suboccipital cavernous sinus. J Neurosurg 1997;86:252-62.

Accepted on 02-07-2009

Source of Support: Nil, Conflict of Interest: None declared. 